\title{
WHITE PAPER \\ Risk Management Program Application for the Component Test Capability
}

Stephanie L. Austad Jeffrey D. Bryan

June 2009
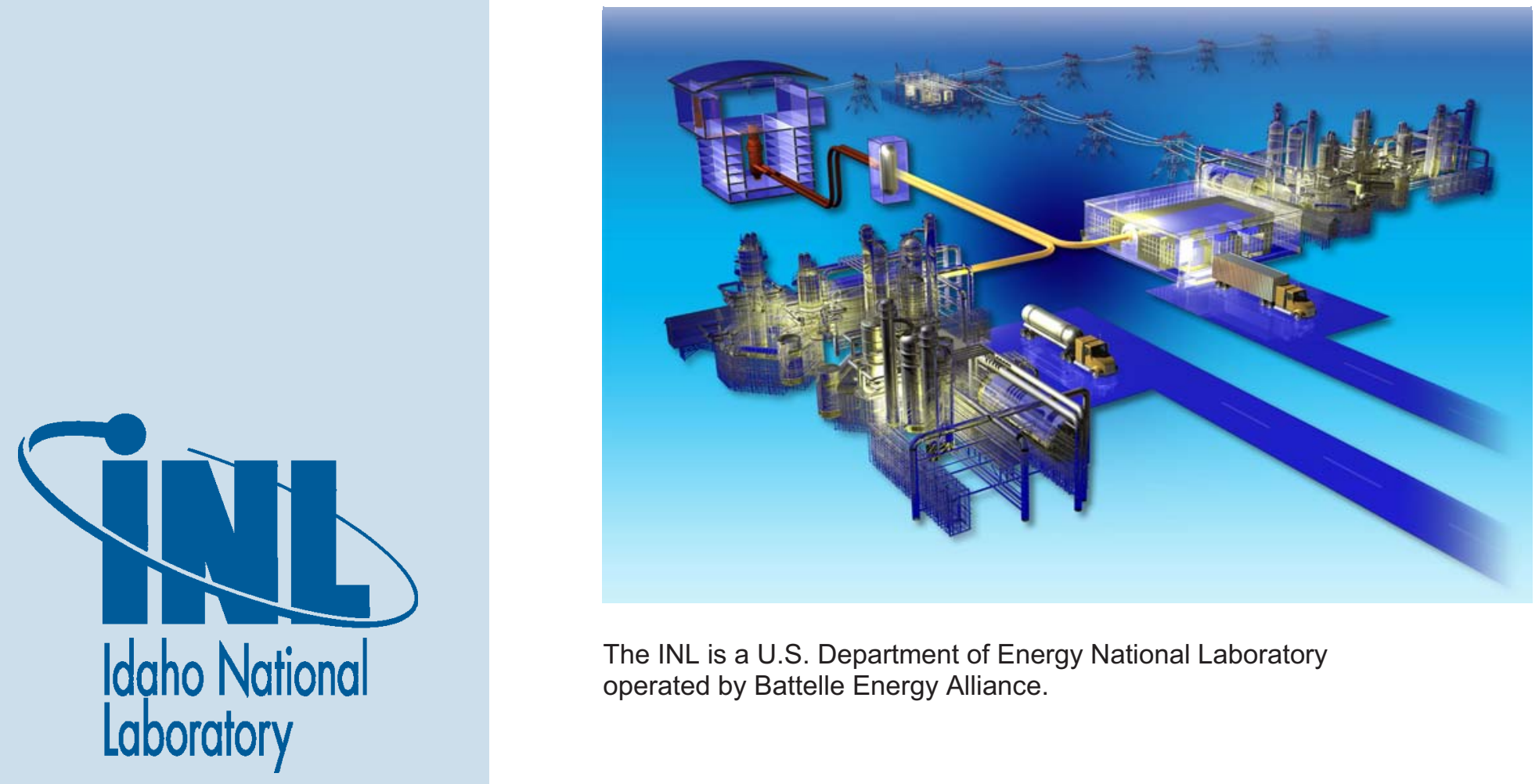

The INL is a U.S. Department of Energy National Laboratory operated by Battelle Energy Alliance. 


\section{DISCLAIMER}

This information was prepared as an account of work sponsored by an agency of the U.S. Government. Neither the U.S. Government nor any agency thereof, nor any of their employees, makes any warranty, expressed or implied, or assumes any legal liability or responsibility for the accuracy, completeness, or usefulness, of any information, apparatus, product, or process disclosed, or represents that its use would not infringe privately owned rights. References herein to any specific commercial product, process, or service by trade name, trade mark, manufacturer, or otherwise, does not necessarily constitute or imply its endorsement, recommendation, or favoring by the U.S. Government or any agency thereof. The views and opinions of authors expressed herein do not necessarily state or reflect those of the U.S. Government or any agency thereof. 
WHITE PAPER

\title{
Risk Management Program Application for the Component Test Capability
}

\author{
Stephanie L. Austad \\ Jeffrey D. Bryan
}

June 2009

\begin{abstract}
Idaho National Laboratory
Next Generation Nuclear Plant Project

Idaho Falls, Idaho 83415
\end{abstract}

Prepared for the

U.S. Department of Energy

Office of Nuclear Energy

Under DOE Idaho Operations Office

Contract DE-AC07-05ID14517 

Next Generation Nuclear Plant Project

WHITE PAPER

Risk Management Program Application for the Component Test Capability

INL/EXT-09-16314

June 2009

Approved by:

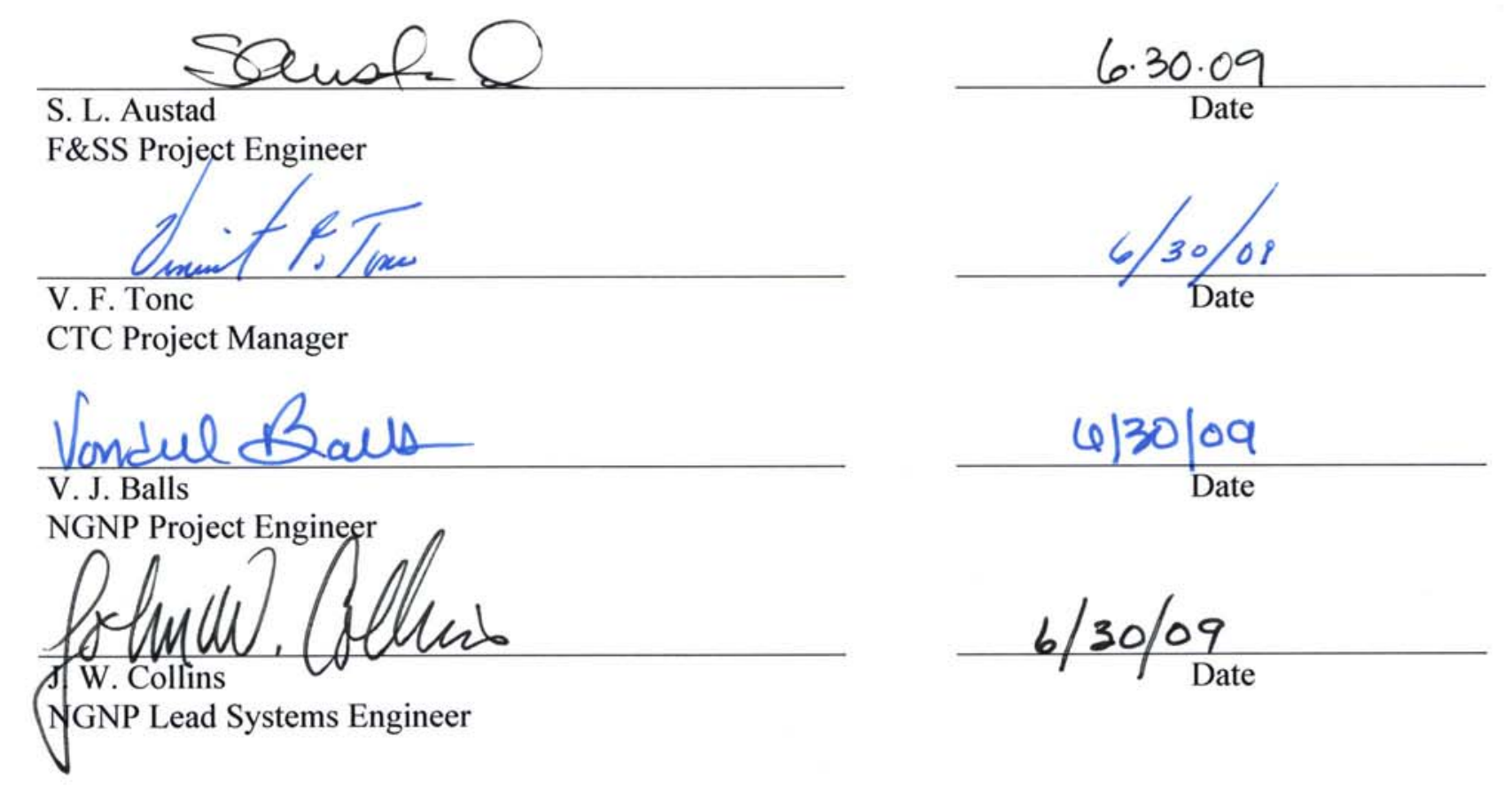





\section{ABSTRACT}

This paper documents the application of the risk management program requirements to Component Test Capability (CTC) Project activities for each CTC alternative. 


\section{CONTENTS}

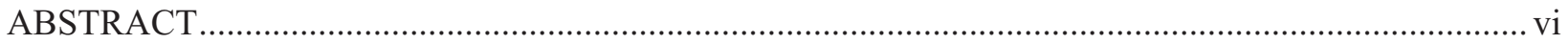

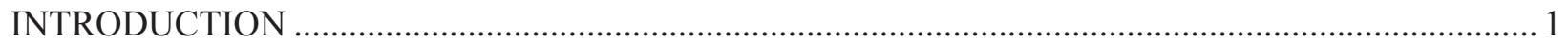

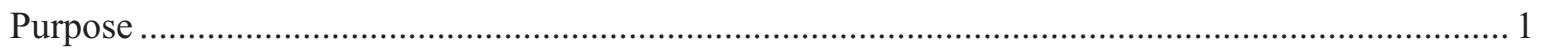

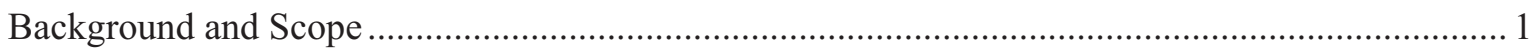

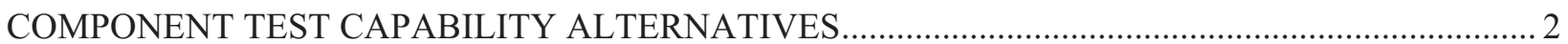

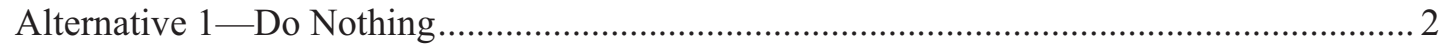

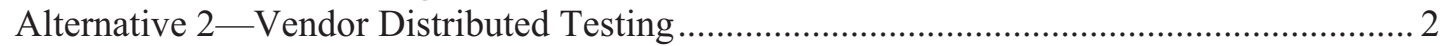

Alternative 3-Modification of Existing Testing Facilities.................................................. 2

Alternative 4-Single, Standalone Component Test Facility ................................................. 3

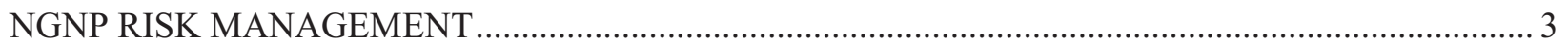

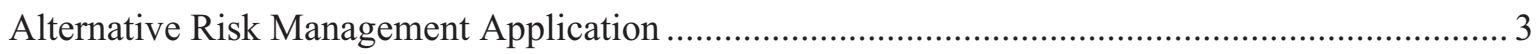

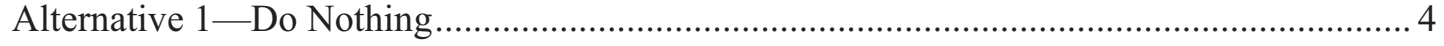

Alternative 2-Vendor Distributed Testing .................................................................... 4

Alternative 3-Existing Testing Facility Modification ...................................................... 5

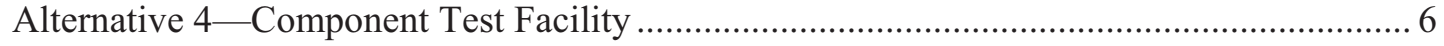

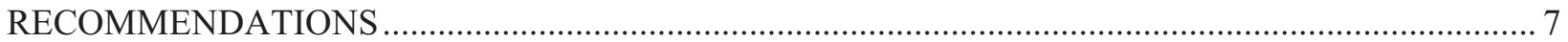




\title{
Risk Management Program Application for the Component Test Capability
}

\author{
INTRODUCTION
}

\section{Purpose}

This paper documents the application of risk management program requirements, processes, and activities to NGNP Component Test Capability (CTC) activities for each CTC alternative. In particular, DOE O 413.3A, "Program and Project Management for the Acquisition of Capital Assets," and DOE G 413.3-7, "Risk Management Guide for Project Management," will apply in the event that Alternative 4, Single, Standalone Component Test Facility (CTF), is selected and approved. As such, it is advisable to begin planning to meet the associated Department of Energy (DOE) requirements and guidance as early in the acquisition process as practicable.

This white paper is intended to assist in this planning and to support associated decision-making activities. Nontechnical risks associated with each alternative will be identified to support the Next Generation Nuclear Plant (NGNP) CTC alternatives analysis. Technical risks are assumed to be addressed through the Technology Development Risk Management modeling process and are inherent to the alternatives.

\section{Background and Scope}

The NGNP Project is conducting a trade study to select a preferred approach for establishing a capability whereby NGNP technology development testing - from material tests up through large-scale integrated tests - can be performed for critical high temperature gas-cooled reactor (HTGR) structures, systems, and components (SSCs). The mission of this capability includes enabling the validation of interfaces, interactions, and performance for critical systems and components prior to installation in the NGNP prototype.

Four alternatives are being evaluated in the trade study. The alternatives for completing the largescale integrated testing necessary to validate the interfaces and performance of critical systems and components prior to installation in the very high temperature reactor plant include:

1. Do nothing - no large-scale testing of NGNP critical SSCs.

2. Distribute the testing requirements to the component and system vendors as part of the specifications for procurement

3. Modify existing facilities (mostly overseas) to support NGNP large-scale testing needs

4. Construct a standalone facility to house and operate test loops designed to meet NGNP large-scale testing needs. 


\section{COMPONENT TEST CAPABILITY ALTERNATIVES}

The following subsections describe the alternatives under consideration for providing the HTGR CTC.

\section{Alternative 1-Do Nothing}

This alternative reflects the NGNP Project adopting a risk acceptance response strategy for the technology risks associated with the critical HTGR SSCs. Under this alternative, no technology development or large-scale testing of critical SSCs will be performed except for integration testing conducted during cold start-up activities for the NGNP prototype. The NGNP design team will be responsible for all SSC engineering and for producing all designs and specifications for the prototype's SSCs.

Prescriptive specifications will be issued by the NGNP Project to vendors who build the SSCs per those specifications. The completed SSCs are shipped to the NGNP prototype where they will be evaluated for acceptance and installed in the prototype reactor. The NGNP Project will retain liability for the reliability, operability, etc., of SSCs, and any defects will have to be addressed and repaired (or replaced) during startup or hot operations.

\section{Alternative 2-Vendor Distributed Testing}

This alternative reflects the NGNP Program adopting a "risk transfer" response strategy to reduce the technology risks associated with critical HTGR SSCs. Under this alternative, risk and technology development associated with critical SSC materials of construction, performance, safety, and operation will be transferred to the vendor through the use of performance specifications. It will be left to the vendors to decide the amount, types, and levels of material and technology development testing that they will perform in order to meet the NGNP performance specifications. Vendors will fund any modification or construction of test capabilities that they need to support their development and testing plans relative to their SSCs. It is expected that the vendors will amortize any test capability implementation costs they incur as part of their SSC bid price. Then, as in Alternative 1, the NGNP Program will perform integrated testing of the critical SSCs as part of cold start-up activities for the NGNP prototype.

\section{Alternative 3-Modification of Existing Testing Facilities}

This alternative reflects the NGNP Program adopting a risk reduction response strategy to address the technology risks associated with critical HTGR SSCs. Under this alternative, one or more existing facilities will be utilized to the fullest extent possible to support material, technology development, largescale, and, possibly, integration testing for critical HTGR SSCs. Technologies to be tested could be those proposed by vendors or those developed by vendors to meet NGNP designs and specifications. Existing facilities under consideration include:

1. Pebble Bed Modular Reactor facilities in the Republic of South Africa where test loops could be designed and installed at either the High Temperature Helium Test Facility or in a new facility.

2. Afrikantov Experimental Machine Building Design Bureau facilities in Russia where test loops could be designed and installed at the Russian Large Scale High Temperature Helium Test Facility. These facilities were built in the 1970s and were operated to the 1980s. They have been deactivated and in a prolonged storage state since that time. 
This alternative can be implemented in several different ways relying on vastly different contracting strategies. Two of the options under investigation are:

- Procure testing services from the user facility. This case has already been tested with NGNP research and development testing performed at university facilities.

- A strategy where DOE is a partner or leaser in an upgraded user facility and retains some ownership in the capital investment.

\section{Alternative 4-Single, Standalone Component Test Facility}

This alternative also reflects the NGNP Project adopting a risk reduction response strategy to address the technology risks associated with critical HTGR SSCs without introducing the residual risks associated with Alternative 3. In this alternative, a single, standalone facility will be constructed to house and operate test loops designed to meet NGNP material, technology development, and large-scale testing needs for the HTGR prototype. The test facility, including any supporting utilities, will be constructed in the United States where it will be fully-funded, owned, and operated by DOE or its representatives. After startup, the CTF could be used to test both NGNP-designed as well as vendor-proposed SSCs. As an added advantage, the CTF will be available for use as a National Scientific User Facility following the accomplishment of NGNP SSC testing scope for ongoing HTGR component development testing and qualification.

Alternative 4 can be assumed to reduce the NGNP technology risk to the highest degree because the facility will allow critical SSCs to be tested in an evolutionary manner up to and including large-scale, integrated testing.

\section{NGNP RISK MANAGEMENT}

It is typical for risk management processes for the initiation, planning, execution, monitoring, and closeout of risks/opportunities to be documented in the project's Project Execution Plan (PEP) or Risk Management Plan (RMP). When written, the RMP is an extension of the PEP and becomes the primary, top level management plan for the risk management activities to be performed throughout the life cycle of the project.

\section{Alternative Risk Management Application}

Battelle Energy Alliance (BEA) is under contract to DOE Idaho Operations Office for management and operations of the Idaho National Laboratory (INL). ${ }^{\text {a }}$ This contract requires BEA to comply with DOE O 413.3A, "Program and Project Management for the Acquisition of Capital Assets" as well as other DOE directives, regulations, and laws. DOE O 413.3A applies to capital asset acquisition projects with values over $\$ 5$ million.

Figure 1 below illustrates how the CTC implementation effort should be covered by the various risk management documents (or PEP, as the case might be), depending on the alternative selected by the NGNP CTC trade study.

\footnotetext{
${ }^{\text {a }}$ Contract number DE-AC07-05ID14517.
} 


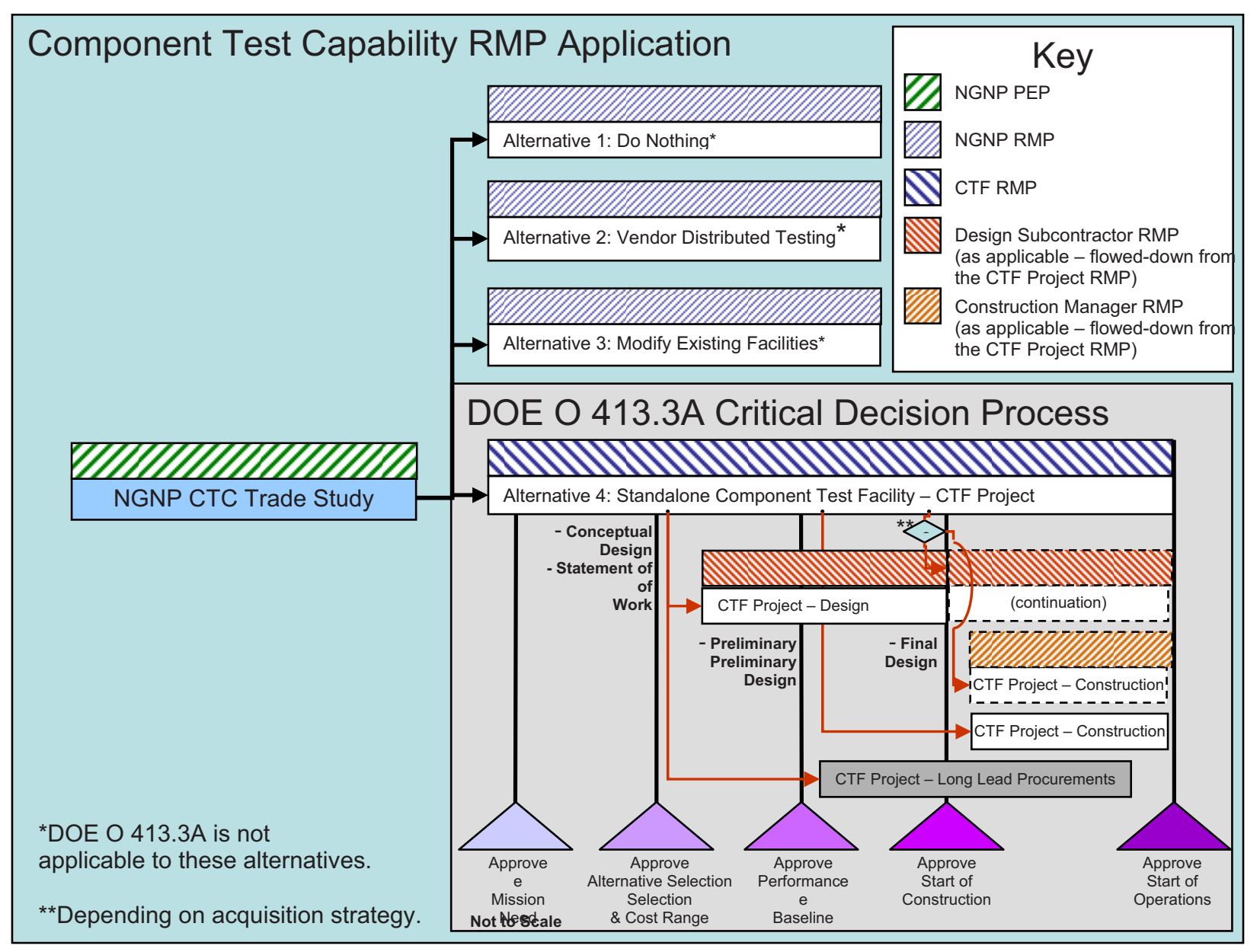

Figure 1. RMP applicability for the CTC alternatives.

\section{Alternative 1-Do Nothing}

This alternative involves no large-scale testing of NGNP critical SSCs except during cold start-up in the plant. Thus, no capability is created under this alternative for mitigating the associated technical and technology development risks and DOE O 413.3A does not apply. Upon acceptance of the SSCs from their respective vendors, the NGNP Project must accept all risk associated with SSC performance, safety, operation, materials of construction, etc., and any resulting rework or schedule delays. These risks will be identified, captured, and managed through the processes outlined in the NGNP RMP.

\section{Alternative 2-Vendor Distributed Testing}

This alternative distributes the testing requirements to the component and system vendors as part of the specifications for procurement. Vendors perform material and technology development testing as they deem necessary in order to meet the performance specifications. As in Alternative 1, no integration testing of NGNP critical SSCs occurs until cold start-up in the plant. Because the vendors fund any modification or construction of testing capabilities needed to support the development and testing of their SSCs, no DOE-owned capability is created under this alternative and DOE O 413.3A does not apply. 
Residual risks that must be accepted by the NGNP Project under this alternative include (but are not limited to):

1. Risk associated with errors or omissions in SSC performance specifications

2. Risk associated with unanticipated transients or adverse interactions between SSCs;

3. Risk associated with latent quality issues not detected until after the "burn-in" or operational period identified in the performance specification

4. Risk associated with selection of vendors who ultimately are not capable of providing SSCs meeting the performance specification - in terms of SSC delivery (NGNP schedule impact), cost, or technical performance.

The risks listed above will be captured and managed under the NGNP RMP processes if this option is chosen. These risks will also be included as part of the decision-making process in the CTC Alternative Analysis.

\section{Alternative 3-Existing Testing Facility Modification}

In this alternative, one or more existing facilities will be modified to support material, technology development, large-scale testing, and, possibly, integration testing of NGNP critical HTGR SSCs. As such, it reduces NGNP technical risk by eliminating or decreasing uncertainties associated with design scale-up, component interface effects that can cause adverse transients or interactions, unit control schemes, and operational performance parameters (i.e., operability, reliability/dependability, availability, maintainability/serviceability/reparability, durability, and sustainability). Because of the limited number of existing facilities available for modification and because these facilities are located overseas, the residual risks that must be accepted by the NGNP Project include (but are not limited to):

1. Risk associated with negative intrusive actions by the foreign government involved

2. Risk associated with delayed or inadequate communications (e.g., due to translator unavailability and translation errors) between the test facility(ies) and the NGNP Project

3. Risk associated with inadequate data package quality due to quality problems inherent to the facility (faulty engineering design or construction)

4. Risk associated with an inadequate level of control over test facility scheduling and prioritization, particularly in the case of partial or nonfunding by DOE

5. Risk associated with an inadequate level of control over test data package quality, particularly in the case of partial or nonfunding by DOE.

As discussed previously, this alternative can also be implemented in several different ways using different contracting strategies. Thus, the selected implementation method can result in varying the amount of residual risk, including the introduction of new risks, as well as different considerations for planning and performing system engineering and technical management:

- In the case where testing services are procured from a user facility after necessary modifications are made, the CTC SE and technical management activities would be primarily concerned with the specification and procurement of the testing services as well as verification of test data deliverables. It is assumed that the requirements for the facility modification are directly derived by the facility owner from the test specifications and attributes of the SSCs to be tested. This type of option does not appear to trigger DOE O 413.3A applicability and the NGNP Program's technical effort relative to mitigating the residual risks should be manageable under the NGNP PEP and the NGNP Risk Management Plan. 
- In the case where DOE is a partner or leaser in an upgraded user facility and retains some ownership in the capital investment, it is conceivable that certain funding methods could have the potential to trigger applicability of DOE O 413.3A requirements for the design, procurement, and construction aspects of the facility upgrade. However, it is assumed that funding will occur through a grant or other mechanism that does not invoke such applicability. In either case, the NGNP Program will need to mitigate the residual risks noted above as well as perform risk and technical management activities, consistent with a systems engineering approach, to protect DOE's ownership stake in the modified facility. These actions will also help to ensure that the facility will be able to provide the requisite testing capability and data quality at completion. As such, DOE G 413.3-7 should be applied as a best management practice and the tailored risk and technical management controls should be covered in and performed per the NGNP PEP or NGNP RMP, as applicable.

\section{Alternative 4-Component Test Facility}

In this alternative, a single, standalone facility, the CTF, will be constructed to house and operate test loops designed to meet NGNP material, technology development, and large-scale testing needs for the HTGR prototype. The CTF, including any supporting utilities, will be constructed in the Unites States where it will be fully-funded, owned, and operated by DOE, or its representatives. This alternative triggers applicable DOE O 413.3A requirements for planning, implementing, and completing the facility using an SE approach. As such, it is advisable to document the planning for and tailoring of risk management processes and activities in an RMP specific to the CTF Project. Figure 2 illustrates the risk management plan application to Alternative 4 throughout the DOE O $413.3 \mathrm{~A}$ process.

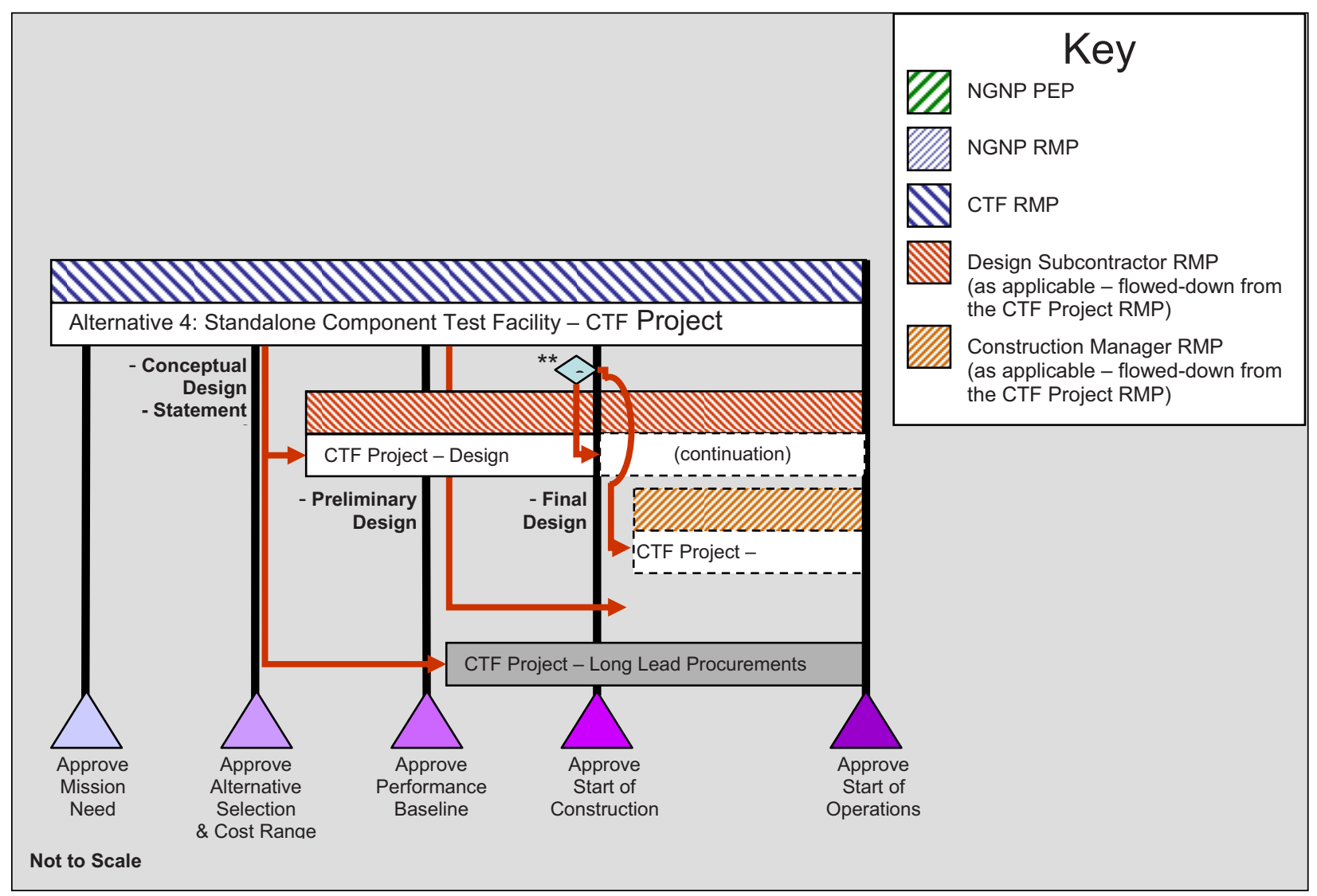

Figure 2. RMP applicability for Alternative 4, Component Test Facility. 


\section{RECOMMENDATIONS}

It is recommended that risk management processes and activities related to the establishment of the CTC be addressed as presented in Figure 1 and as described above according to the selected alternative. The NGNP CTC Alternatives Analysis will be executed under the NGNP PEP. Risk management for Alternatives 1 through will be executed under a NGNP RMP and Alternative 4 risks will be managed under a CTF project-specific RMP. 